\title{
Palatal bone defect mimicking a chronic periapical lesion: a case report emphasizing the importance of the use of a three-dimensional radiographic examination
}

\author{
- Miki Hisatomi Department of Oral and Maxillofacial Radiology, Okayama University, Okayama, Japan \\ - Luciana Munhoz Department of Stomatology, School of Dentistry, São Paulo University, São Paulo, SP, Brazil \\ - Junichi Asaumi Department of Oral and Maxillofacial Radiology, Okayama University, Okayama, Japan \\ - Emiko Saito Arita Department of Stomatology, School of Dentistry, São Paulo University, São Paulo, SP, Brazil
}

\begin{abstract}
Chronic periapical lesion is among the most usual bone pathology observed in human teeth, and it is often first detected by plain radiographs, such as panoramic or periapical radiography. Plain radiographs are widely used in dentistry; however, they have limitations inherent to the technique itself, such as anatomic structures overlapping and lack of information on the extension of the lesion. Therefore, three-dimensional radiographic methods, such as cone beam computed tomography are valuable to accurately assess periapical lesions. Thus, this clinical report describes a case in which the bone radiographic features led to a primary diagnosis of chronic periapical lesion in superior incisors, however, it was a defect in the palatal bone. The resulting radiolucency created by the palatal bone defect overlapped the maxillary bone, mimicking a periapical lesion. Additionally, in the same case, we demonstrate a true chronic periapical lesion in another area that presented as a subtle radiolucency in periapical radiography, however, it was larger than expected when evaluated in Cone Beam Computed Tomography.
\end{abstract}

DESCRIPTORS | Bone Cysts; Computed Tomography; Panoramic Radiography; Periapical Diseases; Oral Diagnosis.

RESUMO | Defeito palatino imitando uma lesão periapical crônica: relato de caso, enfatizando a importância do uso de um exame radiográfico tridimensional - Lesão periapical crônica é uma das patologias ósseas mais comuns em dentes humanos, e é detectada primariamente por radiografia simples, como a panorâmica ou periapical. Radiografias simples são amplamente utilizadas em odontologia; no entanto, elas são limitadas por questões inerentes à técnica em si, tais como a sobreposição de estruturas anatômicas e a falta de informação sobre a extensão da lesão. Portanto, métodos radiográficos tridimensionais, como a tomografia computadorizada de feixe cônico, são valiosos para avaliar com precisão as lesões periapicais. Dessa forma, este relato clínico descreve um caso em que as características radiográficas de osso levaram a um diagnóstico primário de lesão periapical crônica nos incisivos superiores, no entanto, era um defeito palatino. A radiolucência resultante foi causada pelo defeito palatino sobreposto ao osso maxilar, imitando, assim, uma lesão periapical. Além disso, no mesmo caso, demonstramos uma lesão periapical crônica verdadeira em outra área. Essa lesão apareceu como uma radiolucência sutil na radiografia periapical, mas foi maior que o esperado quando avaliada por tomografia computadorizada de feixe cônico.

DESCRITORES

Cistos ósseos; Tomografia Computadorizada; Radiografia Panorâmica; Diagnóstico Oral.

CORRESPONDING AUTHOR | - Luciana Munhoz Department of Stomatology, School of Dentistry, University of São Paulo • Lineu Prestes Avenue, 2227 São Paulo, SP, Brazil • 05508-000 E-mail: dra. lucimunhoz@usp.br

- Received Nov 11, 2017 • Accepted Dec 7, 2017

- Dol http://dx.doi.org/10.11606/issn.2357-8041.clrd.2017..140721 


\section{INTRODUCTION}

Chronic periapical lesions or apical periodontitis is among the most usual bone pathology observed in human teeth, and it is often first detected by plain radiographies, such as panoramic or periapical radiography. The lesion is defined as a destructive-proliferative inflammation that results in lysis of the alveolar bone and apical periodontal elements, ${ }^{1}$ such as periodontal ligament. Due to the bone destructive characteristic caused by periapical lesions, they are diagnosed in radiographic examinations, such as radiolucency near the dental roots, particularly, near to the root apex.

Panoramic radiography is an imaging technique often requested in the beginning of dental treatments, it provides a great amount of useful information about the teeth, dental elements, mineralized tissues and structures in the maxillofacial area. The procedure produces a flattened image of a curved layer, arbitrarily adjusted to the configuration of the maxillofacial structures, ${ }^{1}$ which is performed using an X-ray emitter and a detector panel around the patient with a continuously moving rotation center. The radiographic imaging construction features causes objects outside the focal to appear geometrically distorted, magnified or compressed, or even misplaced. ${ }^{2}$

Periapical radiography is also widely used in dentistry, often as complementary radiographic examination to panoramic radiography or even as the first-choice examination. Despite being considered the gold-standard method to detect chronic periapical lesions and having good accuracy to discriminate lesion from the absence of lesion, ${ }^{3}$ periapical radiographs also have limitations, ${ }^{4}$ and structure overlaps are crucial to this technique. Therefore, three-dimensional radiographic methods, such as cone beam computed tomography (CBCT) are valuable to accurately assess chronic periapical lesions. Three-dimensional scans allow the anatomical and pathological structures to be evaluated in multiple planes, ${ }^{5}$ which can significantly increase the detection of periapical lesions, when compared to plain radiographs. The supplementary data obtained in CBCT are relevant so the professional can provide a more exact diagnosis and prognosis and improve the case technical management.

Thus, this clinical report describes a case in which the bone radiographic characteristics led to a primary diagnosis of chronic periapical lesion in superior incisors, however, it was a palatal bone defect. The resulting radiolucency created by the palatal bone defect overlapped the maxillary bone, mimicking a periapical lesion. Additionally, in the same case, we demonstrate a true chronic periapical lesion in another area that appeared as a subtle radiolucency in periapical radiograph but was larger than expected when evaluated in CBCT.

\section{Case report}

\section{Case history and clinical findings}

The patient on the report is an Asian women (38 years old) who was referred to the Okayama University Hospital for further evaluation of a radiolucent area in the right maxilla, near the root apex of the lateral superior incisor, the area was noticed in a routine panoramic radiograph. The patient had no clinical complaints and her medical history had no previous issues.

The extraoral examination of the patient showed absence of facial asymmetry nor any palpated bulging, and intraoral examination found nothing abnormal. Her dental history was collected, she declared previously undergoing a physical traumatic event and, consequently, she had to perform an endodontic and prosthetic treatment on three upper incisor teeth.

\section{Imaging evaluations}

The panoramic radiograph revealed a roundshaped radiolucency in the right anterior 
maxilla, near the root apex of the lateral superior incisor, with well-defined borders and a unilocular internal appearance. The lesion was homogeneously radiolucent, had no sclerotic borders and was measured at 0.21 centimeters in its largest diameter. No alterations were detected in the surrounding tissues, as shown in Figure 1. Panoramic radiograph was performed using the Veraviewepocs 2D (J Morita Corporation, USA), parameters: $70 \mathrm{kV}$; $8 \mathrm{~mA}$.

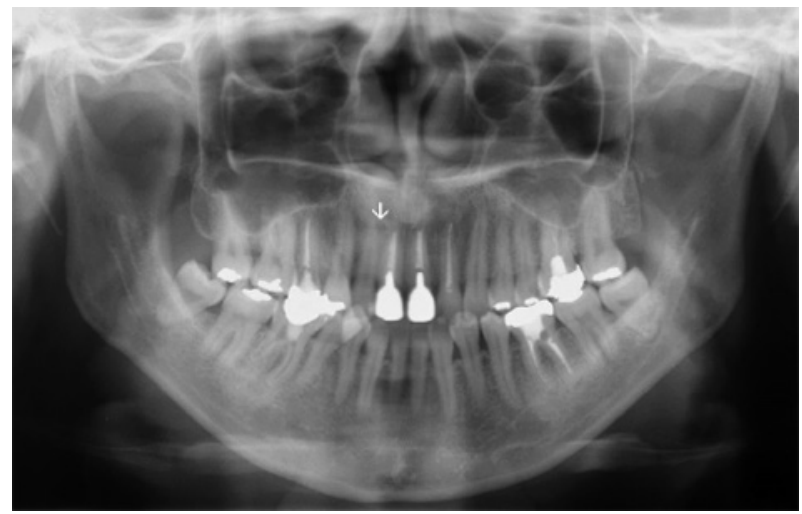

Figure 1 | Panoramic radiograph of the case. Note the tiny radiolucent area (arrow) near the upper lateral incisor, right side. Presence of endodontic treatment can be observed in the adjacent anterior teeth: right and left upper central incisors and left upper lateral incisor, as well as prosthetics in upper central incisors.

The patient received a provisional diagnosis hypothesis for the radiolucent area detected in panoramic radiograph. At this point, chronic periapical lesion was considered as the first and most probable hypothesis, particularly due to the previous history of trauma and the radiographic appearance of the lesion. The patient was then referred to undergo periapical radiography. The periapical radiographs showed that the circleshaped radiolucency was not touching the right lateral upper incisor root, as formerly seemed in panoramic radiography (Figure 2A). The presence of a slight ill-defined radiolucent area, adjacent to root apexes on the left central and lateral incisors was also observed.
Due to this new radiographic finding in periapical radiograph, the hypothesis of periapical lesion on the right side was questioned, despite the possible relation between the radiolucency and a lateral root canal necrosis. A second periapical radiography was performed using the parallax method. The horizontal angulation of the X-ray tube was moved to the distal (left) side. The image obtained showed that the radiolucency moved to the same direction of the tube, which indicates that the lesion should be far from the observer, possibly in the palatal area of the anterior maxilla, as shown in Figure 2B. CBCT was requested for further investigation and as a final examination.

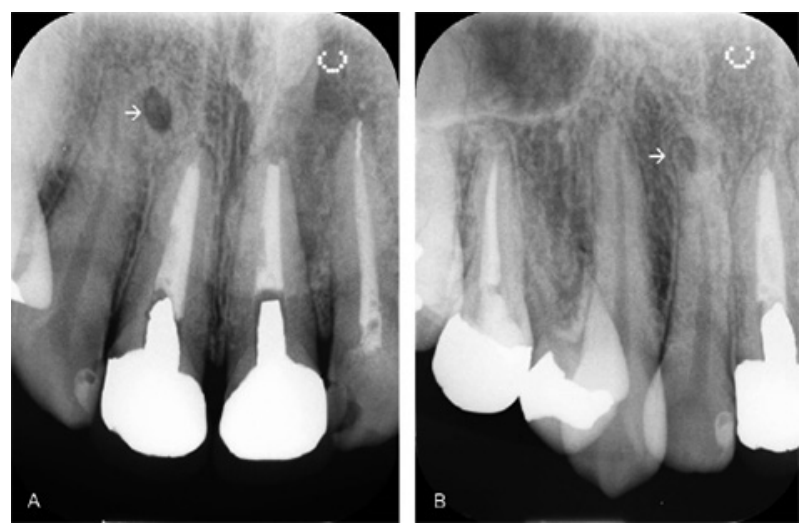

Figure 2 | Intraoral periapical radiograph of the case. Figure 2A: the circle-shaped radiolucency (arrow) is near the upper lateral right incisor root but does not touch the root surface. Left incisors also showed a slight ill-demarcated radiolucent area, adjacent to root apexes. Figure 2B: periapical radiograph using parallaxe technique. Note that the radiolucency has moved to the same direction of the X-ray tube (arrow).

Dedicated high-resolution $\mathrm{CBCT} \quad(3 \mathrm{D}$ Accuitomo CBCT unit - Morita Corporation, USA - parameters 10mA; 60-90KV) was used for CBCT imaging. Acquisition imaging parameters were: $0.5 \mathrm{~mm}$ slice thickness; $1.0 \mathrm{~mm}$ spacing between slices; $250 \mathrm{~mm}$ field of view. CBCT coronal slice revealed a circle-shaped and well-demarcated hypodense area, near to the lateral and central upper incisors, right side, with a hyperdense sclerotic area. The examination 
detected an extensive chronic periapical lesion in the upper incisors on the left side (Figure 3). The left radiolucent area was previously observed as a slight radiolucent ill-defined lesion in plain radiographs.

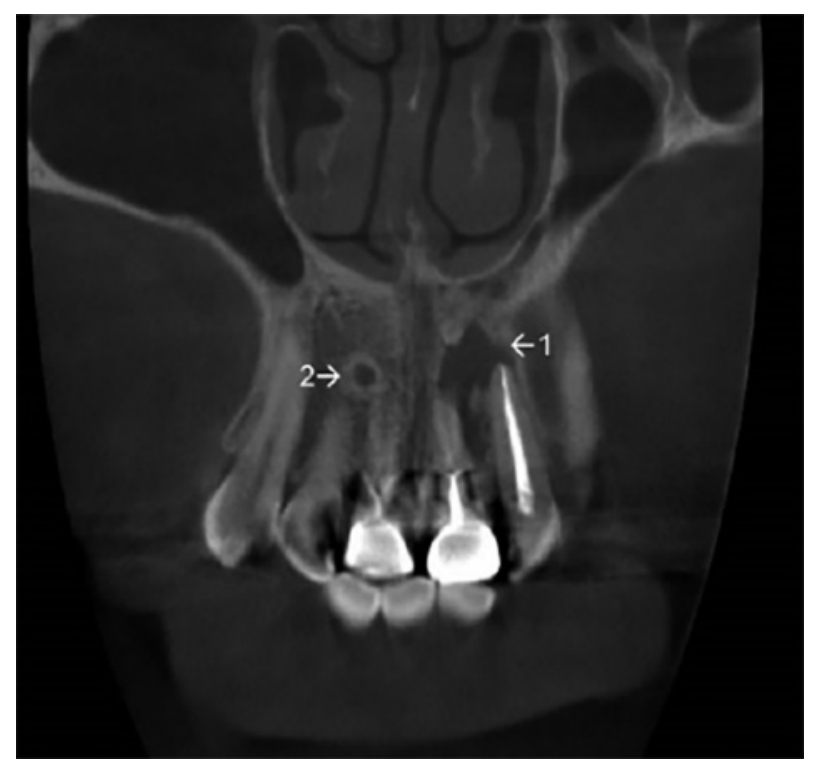

Figure 3 | Coronal slice. A large hypodense area was now detected in the left side, near to left upper incisors area (arrow 1). The presence of a circle-shaped hypodense area near the right upper incisors area was confirmed (arrow 2).

Nevertheless, the axial and sagittal slices of CBCT (Figures 4 and 5) showed that the defect on the right side was not related to the right incisor apexes, but it was a pit in palatal bone. The defect generated a radiolucent area that was overlapped by the upper right incisor roots when investigated in plain radiographs. On the left side, the periapical lesion was larger than expected when evaluated by periapical radiography.

Due to the imaging characteristics shown by CBCT, it was concluded that the well-defined radiolucent area noticed in plain radiographs was not a periapical lesion but was a bone defect in the palatal area.

After the final diagnosis of the bone defect in CBCT, the patient and her dentist were oriented to regular follow-ups.

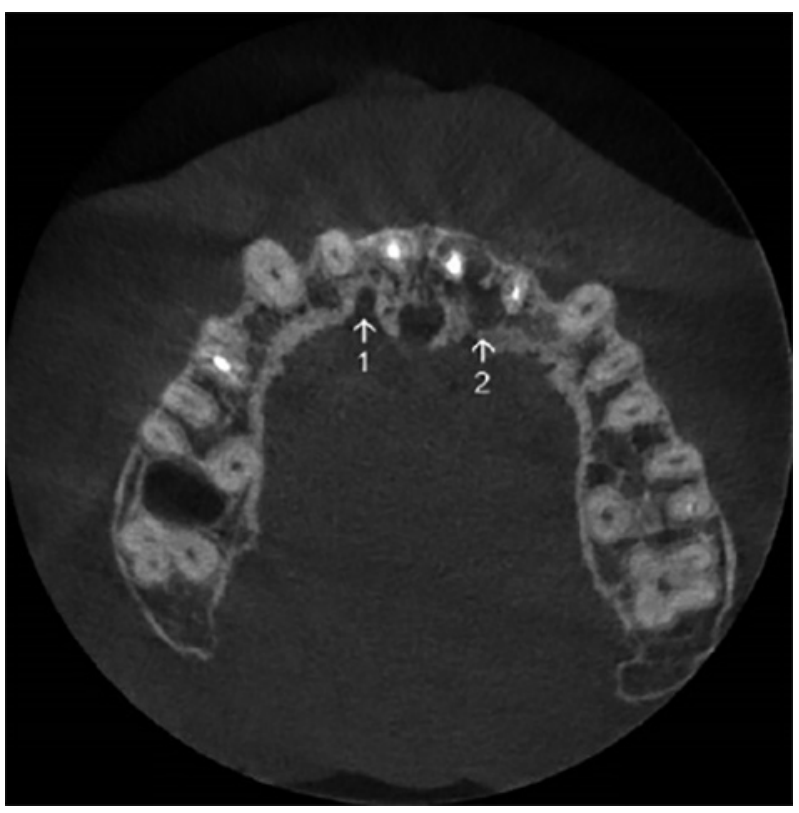

Figure 4 | Axial slice. Note the bone defect in palatal area, not related to the right upper incisors area (arrow 1). On the left side, CPL was larger than previously expected in periapical radiographs (arrow 2).

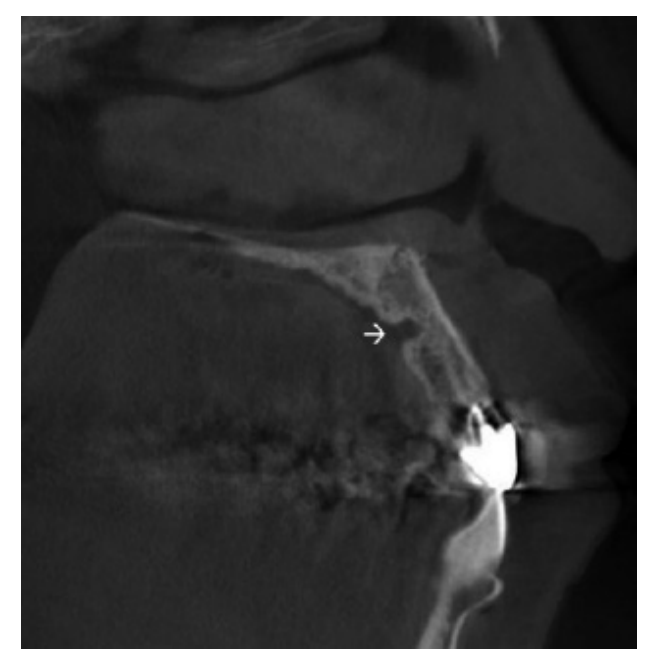

Figure 5 | Sagittal slice. The bone defect in right palatal area is clearly observed (arrow).

\section{DISCUSSION}

This report describes the case of a circle-shaped radiolucency found in a routine radiographic examination. The provisional diagnosis was chronic periapical lesion related to the upper right incisors and the final diagnosis was defined as a bone defect 
in the palatal surface. Another finding was the presence of a large chronic periapical lesion in the left incisors shown by CBCT, which was not detected in plain radiographs. These findings highlight the importance of three-dimensional radiographic examination as a complementary tool to plain radiographs, when radiolucent areas are present.

Radiographic evaluation is indispensable when diagnosing teeth with suspected endodontic pathologies, ${ }^{6}$ as well as radiolucent areas near the dental roots or further investigations in dentistry. Nowadays, periapical imaging is widely used in Endodontics to establish a diagnosis and treatment plan, both before and after the treatment, particularly to monitor bone healing. ${ }^{4}$ Despite of its widespread application, periapical radiograph provides insufficient information. ${ }^{4}$

Periapical images have well-established limitations,${ }^{4}$ which restricts anatomical structural information, such as size, precise location, extension $^{5}$ and effects on adjacent components in the area evaluated. The most evident limitation is the overlap of anatomical structures. Furthermore, the lack of three-dimensional data may mask lesions of notable relevance in Endodontics, or bone defects, as described in the reported case.

Similarly, panoramic radiographs have even more limitations, such as geometric distortion and magnification. ${ }^{5}$ Nevertheless, panoramic radiograph may be used for primary detection of pathological areas and a wide view of the area around the teeth being evaluated. ${ }^{8}$

CBCT can show bone defects and lesion limits on bone margins, which are fundamental to exclude hypotheses of other lesions that would require surgical treatment, such as other cystic aggressive bone lesions. CBCT was also used to establish the negative relation between the defect and the upper incisor root in the reported case. CBCT allows imaging of anatomic osseous structures in three planes, without structures overlapping and spatial distortion. ${ }^{9}$ Another advantage of CBCT is the capability to determine the full extension of a chronic periapical lesion ${ }^{10}$ and its relation with other anatomical structures. ${ }^{6}$

Additionally, regarding to the presence of periapical lesion in the left incisors not clearly observed in plain radiographs, CBCT can provide not only the image of bone resorption near to the root apexes, but it can signalize perforation and root internal resorption. Recently, a considerable number of studies have described the advantage of $\mathrm{CBCT}$ in detecting chronic periapical lesions when compared to other radiographic techniques. ${ }^{10}$

\section{CONCLUSIONS}

In conclusion, even with refined techniques, plain radiographs are limited to showing only twodimensional information. Dentists should be aware of the limitations of two-dimensional radiographs in evaluating radiolucent areas. Relevant information about lesion sizes and limits, as well as the real location of bone defects can be obtained performing three-dimensional examinations, such as CBCT.

\section{REFERENCES}

1. Croitoru IC, CrăiȚoiu Ş, Petcu CM, Mihăilescu OA, Pascu RM, Bobic AG, et al. Clinical, imagistic and histopathological study of chronic apical periodontitis. Rom J Morphol Embryol. 2016;57(2 Suppl):719-28.

2. Riecke B, Friedrich RE, Schulze D, Loos C, Blessmann M, Heiland M, et al. Impact of malpositioning on panoramic radiography in implant dentistry. Clin Oral Investig. 2015 May;19(4):781-9o. doi: 10.1007/soo784-014-1295-1.

3. Leonardi Dutra K, Haas L, Porporatti AL, Flores-Mir C, Nascimento Santos J, Mezzomo LA, et al. Diagnostic Accuracy of Cone-beam Computed Tomography and Conventional Radiography on Apical Periodontitis: A Systematic Review and Meta-analysis. J Endod. 2016 Mar;42(3):356-64. doi: 10.1016/j.joen.2015.12.015.

4. Patel S, Dawood A, Whaites E, Pitt Ford T. New dimensions in endodontic imaging: part 1 . Conventional and alternative 
radiographic systems. Int Endod J. 2009 Jun;42(6):447-62. doi: 10.1111/j.1365-2591.2008.01530.x.

5. Patel S, Dawood A, Wilson R, Horner K, Mannocci F. The detection and management of root resorption lesions using intraoral radiography and cone beam computed tomography: an in vivo investigation. Int Endod J. 2009 Sep;42(9):831-8. doi: 10.1111/j.1365-2591.2009.01592.x.

6. López FU, Kopper PM, Cucco C, Della Bona A, de Figueiredo JA, Vier-Pelisser FV. Accuracy of cone-beam computed tomography and periapical radiography in apical periodontitis diagnosis. J Endod. 2014 Dec;40(12):2057-60. doi: 10.1016/j. joen.2014.09.003.

7. Segura JJ, Jiménez-Rubio A, Cabrera R. Intracoronal radiolucency in an incompletely erupted permanent molar with a diagnosis of pericoronitis: importance of radiographic exami- nation. Oral Surg Oral Med Oral Pathol Oral Radiol Endod. 1998 Apr;85(4):461.

8. Lee SS, Park SH, Kim JK, Kim N, Lee J, Park BJ, et al. Panoramic endoluminal display with minimal image distortion using circumferential radial ray-casting for primary three-dimensional interpretation of CT colonography. Eur Radiol. 2009 Aug;19(8):1951-9. doi: 10.1007/s00330-009-1362-1.

9. Mengel R, Kruse B, Flores-de-Jacoby L. Digital volume tomography in the diagnosis of peri-implant defects: an in vitro study on native pig mandibles. J Periodontol. 2006 Jul;77(7):1234-41. doi: 10.1902/jop.2006.050424.

10. Garcia de Paula-Silva FW, Hassan B, Bezerra da Silva LA, Leonardo MR, Wu MK. Outcome of root canal treatment in dogs determined by periapical radiography and cone-beam computed tomography scans. J Endod. 2009 May;35(5):723-6. doi: 10.1016/j.joen.2009.01.023. 